\title{
Astragaloside IV prevents endothelial dysfunction by improving oxidative stress in streptozotocin-induced diabetic mouse aortas
}

\author{
YANG ZHANG $^{1}$, XIAO-DONG MAO ${ }^{2}$, AI-LI CAO ${ }^{2}$, SHUANG CHU ${ }^{2}$, ZHI-JUN LI $^{1}$, \\ YUN-MAN WANG ${ }^{1}$, WEN PENG $^{1}$, LI WANG $^{2}$ and HAO WANG ${ }^{1}$ \\ ${ }^{1}$ Department of Nephrology, ${ }^{2}$ Laboratory of Renal Disease, Putuo Hospital, \\ Shanghai University of Traditional Chinese Medicine, Shanghai 200062, P.R. China
}

Received April 16, 2018; Accepted June 15, 2021

DOI: $10.3892 /$ etm.2021.10631

\begin{abstract}
Oxidative stress serves a role in endothelial dysfunction exhibited by patients with diabetes mellitus. Astragaloside IV (AS-IV) is a major active ingredient of Radix Astragali, which is considered to exhibit vasoprotective effects through unknown mechanisms. Thus, the current study was performed to investigate the protective effects of AS-IV in streptozotocin (STZ)-induced endothelial dysfunction and to explore whether antioxidant mechanisms were involved. The protective effects of AS-IV on the endotheliumdependent relaxation and contraction of aortic rings were determined by isometric tension recordings. NADPH subunits and endothelial nitric oxide synthase (eNOS) expression was identified via western blotting. Superoxide dismutase and malondialdehyde levels were assayed using ELISA. Furthermore, the generation of reactive oxygen species (ROS) and nitric oxide (NO) was detected via dihydroethidium and 4,5-diaminofluorescein diacetate staining, respectively. The results revealed that STZ-injected mice exhibited increased aortic endothelium-dependent vasoconstriction and decreased vasorelaxation to acetylcholine. However, AS-IV treatment reversed these effects. $\mathrm{N}^{\mathrm{G}}$-nitro-L-arginine was subsequently used to completely inhibit impaired relaxation. Accordingly, impaired NO generation was restored following AS-IV treatment by increasing eNOS phosphorylation levels. Furthermore, ROS formation was also depressed following AS-IV treatment compared with that in STZ-injected mice. AS-IV also decreased the expression of various NADPH
\end{abstract}

Correspondence to: Professor Hao Wang, Department of Nephrology, Putuo Hospital, Shanghai University of Traditional Chinese Medicine, 164 Lanxi Road, Shanghai 200062, P.R. China E-mail: wang402hao@163.com

Ms. Li Wang, Laboratory of Renal Disease, Putuo Hospital, Shanghai University of Traditional Chinese Medicine, 164 Lanxi Road, Shanghai 200062, P.R. China

E-mail: wanglitcm2007@163.com

Key words: diabetic vascular complications, endothelial dysfunction, oxidative stress, nitric oxide, astragaloside IV subunits, including human neutrophil cytochrome $b$ light chain, neutrophil cytosolic factor 1, NADPH oxidase (NOX)2, NOX4 and Rac-1. The results of the current study may provide novel evidence that diabetes-induced vascular injury arises from either the inhibition of eNOS or the activation of NOX-derived ROS generation. In addition, the results warrant further investigation into the application of AS-IV treatment, leading to the improvement of oxidative stress, in patients with diabetes exhibiting endothelial dysfunction.

\section{Introduction}

Endothelial dysfunction, which is the loss of balance between vasodilator and vasoconstrictor factors in blood vessels, is a well-accepted precursor of cardiovascular disorder pathogenesis, occurring at very early stages of diabetes (1-3). Severe hyperglycemia, as well as functional and structural alterations in the myocardium and vasculature, are the most typical characteristics of patients with type 1 diabetes mellitus (T1D) (4). Hyperglycemia can reduce the bioavailability of nitric oxide (NO), which is a classical anti-atherosclerosis substance that impairs endothelium-dependent vasodilatation in T1D (4). It has also been demonstrated that hyperglycemia is associated with the increased production of free radicals and oxidative stress (5). Increased oxidative stress appears to be the critical alteration that drives the activation of many cellular pathways, such as nuclear factor- $\kappa \mathrm{B}, \mathrm{p} 38$ mitogen-activated protein kinase, NH2-terminal Jun kinases/stress-activated protein kinases, hexosamines and others (6). So inhibiting this process may be beneficial for improving endothelial dysfunction to prevent or delay the onset of vascular-related T1D complications $(7,8)$.

Reactive oxygen species (ROS), known as free radicals, serve a pivotal role in the etiology and progression of endothelial and vascular dysfunctions by creating vascular oxidative stress (9). The exacerbation of ROS production or insufficient scavenging impairs biological processes, including endothelial function in the vascular system of patients with diabetes mellitus $(10,11)$. Aside from mitochondria and other enzymes, NADPH oxidase (NOX) is a prevalent source of ROS. The NOX family represent critical determinants of the redox state within the vessel wall that dictate, in part, the pathophysiology of several vascular phenotypes (12). Previous studies have 
demonstrated that decreasing the production of ROS derived from NOX is helpful for the protection of vascular endothelial function (13-15).

Astragaloside IV (AS-IV), a representative natural saponin molecule isolated from Radix Astragali, possesses a variety of pharmacological properties against inflammation (16), hypertension (17), oxidative stress (18) and fibrosis (19). A previous study reported that AS-IV significantly inhibited renal oxidative stress and apoptosis in streptozotocin (STZ)-induced diabetic rats (20). An additional study revealed that AS-IV is a candidate for podocyte injury protection via the ER stress pathway in T1D mice (21). It was also reported that AS-IV treatment ameliorated oxidative injury to protect retinal capillary endothelial cells, diabetic gastric mucosa and the developing brain, and to protect against pulmonary fibrosis (22-26). However, the precise mechanisms of AS-IV on oxidative stress-induced injury in diabetic mouse aortas have not yet been fully elucidated. Consequently, the aim of the present study was to evaluate the effects of AS-IV in diabetic-induced aortic tissue injury, and to identify the efficacy as a result of inhibiting oxidative stress levels.

\section{Materials and methods}

Animals. All experimental procedures were conducted in accordance with the National Institutes of Health Guide for the Care and Use of Laboratory Animals, and were approved by the Ethics Committee of Putuo Hospital, Shanghai University of Traditional Chinese Medicine (Shanghai, China). The dose of AS-IV used in the present study was selected according to the body surface area normalization method (27) and STZ-induced diabetes was generated as previously described (21). Animals received free access to water and standard rat chow, and were housed at constant room temperature $\left(25^{\circ} \mathrm{C}\right)$ and humidity $(75 \%)$, and were exposed to a $12 \mathrm{~h} \mathrm{light}$ and $12 \mathrm{~h}$ dark cycle. Male, 6-week-old, C57BL/6J mice $(\mathrm{n}=40)$ were purchased from Shanghai SLAC Laboratory Animal Co., Ltd. After 2 weeks of acclimation, diabetes was induced via the intraperitoneal injection of freshly prepared STZ (Sigma-Aldrich; Merck KGaA; dissolved in $0.01 \mathrm{M}$ citrate buffer, $\mathrm{pH} 4.5$ ) at $100 \mathrm{mg} / \mathrm{kg} / \mathrm{day}$ for 2 consecutive days. At 1 week post-STZ injection, fasting blood glucose level was measured to verify the development of diabetes. Blood samples $(\sim 50 \mu \mathrm{l})$ were collected from the tail vein, and mice with blood glucose $>350 \mathrm{mg} / \mathrm{dl}$ were randomly separated into diabetes mellitus (DM) and DM+AS-IV (3, 6 and $12 \mathrm{mg} / \mathrm{kg}$ ) groups ( $\mathrm{n}=8$ for each group). Each group was treated with $0.5 \%$ carboxymethyl cellulose (CMC; $12 \mathrm{mg} / \mathrm{kg}$ ) or AS-IV (3, 6 and $12 \mathrm{mg} / \mathrm{kg}$ ) by daily gavage for 8 weeks. Moreover, mice without STZ treatment were labelled as the control $(\mathrm{n}=8)$, and were also administered with $0.5 \% \mathrm{CMC}$ in $12 \mathrm{mg} / \mathrm{kg}$. AS-IV (Shanghai Bogoo Biological Technology Co., Ltd.; 98\% purity) was suspended in $0.5 \% \mathrm{CMC}$, and the three DM+AS-IV group mice were administered with AS-IV in 3,6 and $12 \mathrm{mg} / \mathrm{kg}$, respectively. A total of 9 weeks following the start of STZ treatment, the mice were euthanized with pentobarbital sodium $(120 \mathrm{mg} / \mathrm{kg}$, i.p.). The thoracic aortae were dissected from the adherent fat and connective tissues for further analysis.

Isometric tension recordings. The thoracic aortae were dissected and immediately placed in a petri dish filled with an oxygenated and ice-cold Krebs-Henseleit solution (119 mM $\mathrm{NaCl}, 4.7 \mathrm{mM} \mathrm{KCl}, 2.5 \mathrm{mM} \mathrm{CaCl}_{2}, 1 \mathrm{mM} \mathrm{MgCl} 2,25 \mathrm{mM}$ $\mathrm{NaHCO}_{3}, 1.2 \mathrm{mM} \mathrm{KH} \mathrm{PO}_{4}$ and $11 \mathrm{mM}$ D-glucose; $\mathrm{pH}$ 7.4). Samples were then sliced into small rings ( $2 \mathrm{~mm}$ in length). Rings were mounted on a wire myograph system (DMT 620 M; Danish Myo Technology A/S) for recording isometric tension using Labchart 7.0 software (AD Instruments, Inc.). The organ chamber was filled with $5 \mathrm{ml} \mathrm{Krebs}$ solution, $95 \% \mathrm{O}_{2}$ and $5 \% \mathrm{CO}_{2}$ at $37^{\circ} \mathrm{C}$. Each ring was stretched to an optimal baseline tension of $3 \mathrm{mN}$ and equilibrated for at least $1 \mathrm{~h}$ before being stimulated with pharmacological agents. The ring was first contracted by $60 \mathrm{mM} \mathrm{KCl}$. After elution and a further equilibration, aortae were stimulated with phenylephrine (Phe; $10^{-6} \mathrm{M}$; Sigma-Aldrich; Merck KGaA) followed by acetylcholine (ACh; $10^{-6} \mathrm{M}$; Sigma-Aldrich; Merck $\mathrm{KGaA}$ ) to assess the function of endothelial cells.

To assess endothelial-dependent vasorelaxation, Phe $\left(10^{-6} \mathrm{M}\right)$ was used to evoke a stable contraction and then relaxed by accumulative concentrations of ACh $\left(10^{-9}, 10^{-8.5}\right.$, $10^{-8}, 10^{-7.5}, 10^{-7}, 10^{-6.5}, 10^{-6}, 10^{-5.5}, 10^{-5} \mathrm{M}$ ) for comparison in aortae derived from control, DM and DM+AS-IV (3, 6 and $12 \mathrm{mg} / \mathrm{kg}$ ) mice. To confirm the role of basal NO production in the reduced vasorelaxation state, the same experiments were performed in rings after $30 \mathrm{~min}$ at $37^{\circ} \mathrm{C}$ exposure to $\mathrm{N}^{\mathrm{G}}$-nitro-L-arginine (L-NAME; $10^{-4} \mathrm{M}$; Sigma-Aldrich, Merck KGaA). Furthermore, to assess the effect of AS-IV to ACh-induced vasoconstriction, cumulative concentration-response curves were generated with $\mathrm{ACh}\left(10^{-8}, 10^{-7.5}\right.$, $\left.10^{-7}, 10^{-6.5}, 10^{-6}, 10^{-5.5}, 10^{-5}, 10^{-4.5}, 10^{-4} \mathrm{M}\right)$ that pre-contracted with $60 \mathrm{mM} \mathrm{KCl}$.

Western blot analysis. After the mice had been euthanized, thoracic aortae were rapidly removed and stored at $-80^{\circ} \mathrm{C}$. The aortae were lysed in RIPA lysis buffer $[50 \mathrm{mmol} / \mathrm{l}$ Tris $(\mathrm{pH}, 7.5) ; 1 \mathrm{mmol} / \mathrm{l}$ EDTA; $150 \mathrm{mmol} / \mathrm{l} \mathrm{NaCl} ; 20 \mathrm{mmol} / \mathrm{l}$ NaF; $0.5 \%$ NP-40; $10 \%$ glycerol; $1 \%$ protease inhibitor cocktail and $1 \%$ phosphatase inhibitor cocktail] via sonication on ice ( $3 \mathrm{sec} / \mathrm{ml}$, five times at setting 5 with a $30 \mathrm{sec}$ break between each sonication). The resultant supernatants were collected and protein concentration was determined using a BCA protein assay kit (Pierce; Thermo Fisher Scientific, Inc.). Equal quantities of protein $(20 \mu \mathrm{g})$ were separated by $10 \%$ SDS-PAGE and transferred to PVDF membranes (Pierce; Thermo Fisher Scientific, Inc.). Following blocking with $5 \%$ BSA in TBS-Tween-20 for $2 \mathrm{~h}$, the membrane was incubated with primary antibodies including: p22phox (1:500; cat. no. sc-20781; Santa Cruz Biotechnology, Inc.); p47phox (1:500; cat. no. sc-14015; Santa Cruz Biotechnology, Inc.); 67phox (1:500; cat. no. sc-15342; Santa Cruz Biotechnology, Inc.); NOX2 (1:500; cat. no. sc-130543; Santa Cruz Biotechnology, Inc.); NOX4 (1:500; cat.no. sc-21860; Santa Cruz Biotechnology, Inc.); Rac-1 (1:200; cat. no. sc-95; Santa Cruz Biotechnology, Inc.), eNOS (1:500; cat. no. ab66127; Abcam); phosphorylated $\left(p^{1177}\right)$ eNOS (1:500; cat. no. ab195944, Abcam) and $\beta$-actin (1:1,000; cat. no. 4970; Cell Signaling Technology, Inc.). After three washes in TBS-Tween-20, the membranes were incubated with the HRP-labeled goat anti-rabbit secondary antibody (1:5,000; cat. no. BA1039; Wuhan Boster Biotech Co. Ltd.) for $1 \mathrm{~h}$ at room temperature. Protein bands were visualized using Immobilon Western Chemiluminescent HRP 
Table I. Effect of AS-IV on the $\mathrm{E}_{\max }$ and $\mathrm{pD} 2$ values of ACh-induced relaxation and contraction dose-response curves of the aortas isolated from control, DM and DM+AS-IV $(3,6,12 \mathrm{mg} / \mathrm{kg})$ mice.

\begin{tabular}{|c|c|c|c|c|}
\hline \multirow[b]{2}{*}{ Groups } & \multicolumn{2}{|c|}{ ACh (relaxation) } & \multicolumn{2}{|c|}{ ACh (contraction) } \\
\hline & $\mathrm{E}_{\max }$ & $\mathrm{pD}_{2}$ & $\mathrm{E}_{\max }$ & $\mathrm{pD}_{2}$ \\
\hline Control & $89.80 \pm 1.62$ & $7.41 \pm 0.06$ & $11.54 \pm 2.93$ & $5.94 \pm 0.25$ \\
\hline DM & $66.74 \pm 4.34^{\mathrm{b}}$ & $7.01 \pm 0.09^{\mathrm{a}}$ & $82.24 \pm 4.22^{\mathrm{a}}$ & $7.30 \pm 0.26^{\mathrm{a}}$ \\
\hline DM+AS-IV 3 mg $/ \mathrm{kg}$ & $71.23 \pm 3.39$ & $6.99 \pm 0.09$ & $73.37 \pm 3.63$ & $6.92 \pm 0.15$ \\
\hline $\mathrm{DM}+\mathrm{AS}-\mathrm{IV} 6 \mathrm{mg} / \mathrm{kg}$ & $85.00 \pm 1.67^{\mathrm{d}}$ & $7.02 \pm 0.09$ & $62.25 \pm 6.35^{\mathrm{c}}$ & $6.33 \pm 0.27^{\mathrm{c}}$ \\
\hline DM+AS-IV 12 mg/kg & $86.27 \pm 1.38^{\mathrm{e}}$ & $7.33 \pm 0.07^{\mathrm{c}}$ & $52.19 \pm 4.66^{\mathrm{e}}$ & $6.09 \pm 0.35^{\mathrm{c}}$ \\
\hline
\end{tabular}

Data are expressed as the mean $\pm \mathrm{SEM}(\mathrm{n}=6-8) .{ }^{\mathrm{a}} \mathrm{P}<0.01$ and ${ }^{\mathrm{b}} \mathrm{P}<0.001$ vs. control mice. ${ }^{\mathrm{c}} \mathrm{P}<0.05,{ }^{\mathrm{d}} \mathrm{P}<0.01$ and ${ }^{\mathrm{e}} \mathrm{P}<0.001$ vs. mice with $\mathrm{DM}$. AS-IV, Astragaloside; $\mathrm{E}_{\max }$, maximal response; $\mathrm{pD} 2,\left(-\log \mathrm{EC}_{50}\right)$; ACh, acetylcholine; DM, diabetes mellitus.

Substrate (MilliporeSigma). The ratio of each protein was normalized to $\beta$-actin and analyzed using ImageJ software, version 1.37 (National Institutes of Health).

ELISA investigation. After mice had been euthanized, thoracic aortae were rapidly removed and cleaned of adhering connective tissue with PBS. Total superoxide dismutase (T-SOD) was evaluated using an ELISA kit (cat. no. A001-1-2; Nanjing Jiancheng Bioengineering Institute) with hydroxylamine method. In brief, a total of $100 \mu 1$ SOD sample was prepared for every $10 \mathrm{mg}$ of tissue, and homogenized on ice. Samples were centrifuged for $5 \mathrm{~min}$ at $12,000 \mathrm{~g}$ and $4^{\circ} \mathrm{C}$, and the supernatant was subsequently extracted for measurement. The supernatant and SOD detection working solution were mixed at a $1: 20$ ratio and maintained at $37^{\circ} \mathrm{C}$ for $30 \mathrm{~min}$, before chromogenic agent was added. At each endpoint, red substances were detected at an absorbance of $550 \mathrm{~nm}$ after $10 \mathrm{~min}$ at $37^{\circ} \mathrm{C}$. SOD activity unit was converted into $\mathrm{U} / \mathrm{mg}$ protein according to the protein concentration and dilution ratio of the sample.

The malondialdehyde (MDA) was evaluated using an ELISA kit (cat. no. A003-1-2, Nanjing Jiancheng Bioengineering Institute) with thiobarbituric acid (TBA) method, as commercially recommended. Briefly, a total of $100 \mu 1$ MDA sample was prepared for every $5 \mathrm{mg}$ of tissue, and homogenized on ice. Samples were centrifuged for $5 \mathrm{~min}$ at $12,000 \mathrm{~g}$ and $4^{\circ} \mathrm{C}$, and the supernatant was subsequently extracted for measurement. The supernatant and MDA detection working solution were mixed at a ratio of 1:2 and heated at $95^{\circ} \mathrm{C}$ in acidic conditions for $40 \mathrm{~min}$. The samples were cooled to room temperature $\left(25^{\circ} \mathrm{C}\right)$ with running water and centrifuged at $4,000 \mathrm{rpm}$ and $25^{\circ} \mathrm{C}$ for $10 \mathrm{~min}$. The resulting reaction yields a pink reactive TBA substance, which was measured at $532 \mathrm{~nm}$. The MDA content in the sample solution was calculated and converted to $\mathrm{nmol} / \mathrm{mg}$ according to the protein concentration.

Fluorescence analysis. As previously described (28), in situ ROS and NO generation was observed with dihydroethidium (DHE; Sigma-Aldrich; Merck KGaA) and 4,5-diaminofluorescein diacetate (DAF-2 DA; Sigma-Aldrich; Merck KGaA) fluorescence probes, respectively. In brief, frozen thoracic aortas were cut into $4-\mu \mathrm{m}$ thick slices. DHE $(10 \mu \mathrm{M})$ was directly added onto the slices and incubated for $30 \mathrm{~min}$ at $37^{\circ} \mathrm{C}$. Samples were then washed with PBS to remove free DHE molecules. Red fluorescence was monitored via a Nikon E 600 fluorescence microscope (Nikon TE2000; Nikon Corporation). Images were obtained using an excitation wavelength of 520-540 $\mathrm{nm}$ and a rhodamine emission filter, and the fluorescence intensity was analyzed. DAF-2 DA $(10 \mu \mathrm{M})$ was also added and incubated with different slices using the same procedure, as previously described. Green fluorescence was monitored under the same fluorescence microscope fitted with a 40x PlanFluor objective and a fluorescein isothiocyanate filter set. The signals were acquired using NIS-Elements software version 3.0 (Nikon Corporation), and the fluorescence intensity was assessed.

Statistical analysis. Relaxations were expressed as the percentage of Phe-induced contractions. ACh-induced contractions were expressed as the percentage of $\mathrm{KCl}(60 \mathrm{mM})$-induced contractions, which were compared among different groups. Concentration relaxation curves were analyzed to estimate maximal response $\left(\mathrm{E}_{\max }\right.$ values and $\mathrm{pD} 2\left(-\log \mathrm{EC}_{50}\right)$ as the negative logarithm of the drug concentration that produced $50 \%$ of the $\mathrm{E}_{\max }$. One-way ANOVA and subsequent Tukey's post hoc testing was used for performing statistical comparisons among experimental groups using GraphPad Prism 5.0 software (GraphPad Software, Inc.). All experiments were repeated a minimum of three times and results are presented as the mean \pm SEM $. \mathrm{P}<0.05$ was considered to indicate a statistically significant difference.

\section{Results}

$A S-I V$ improves the endothelium-dependent relaxation $(E D R)$ and contraction (EDC) of aortae in STZ-induced diabetic mice. Thoracic aortae isolated from STZ-induced diabetic mice were used to measure the isometric tension. As a known activator of endothelium-dependent relaxation, acetylcholine (ACh)-induced EDR were detected after the rings had been precontracted with phenylephrine (Phe). As presented in representative traces (Fig. 1A) and summarized data (Fig. 1B; Table I), the response to accumulative 
A

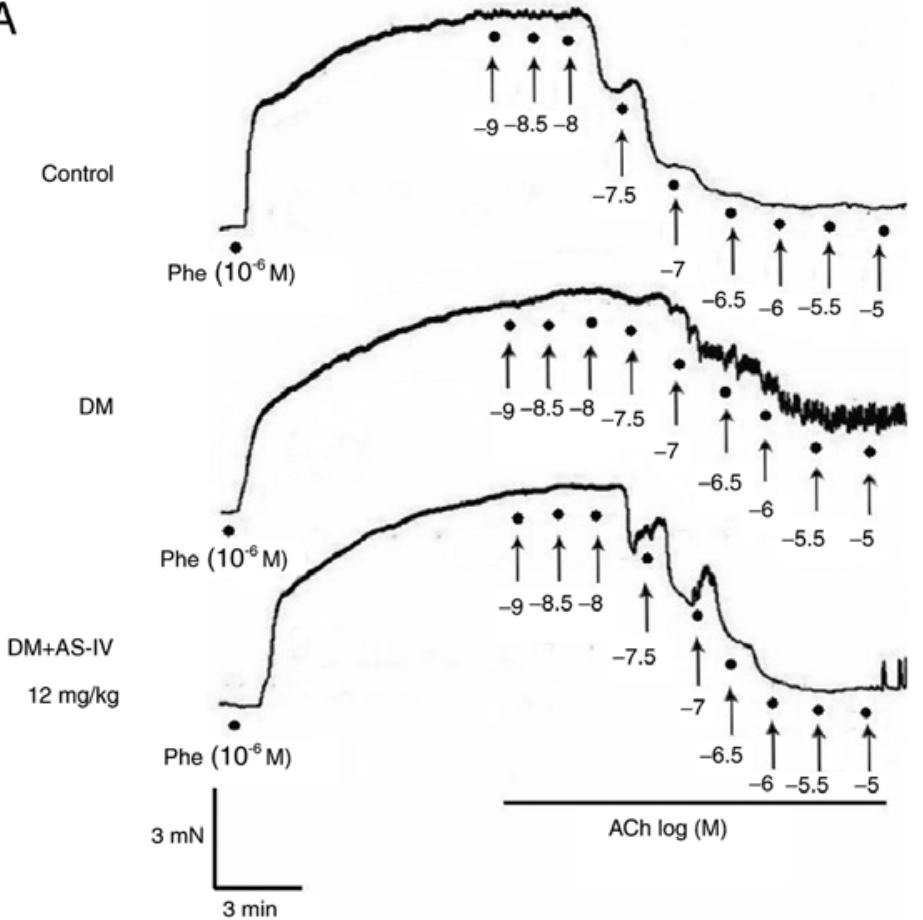

B

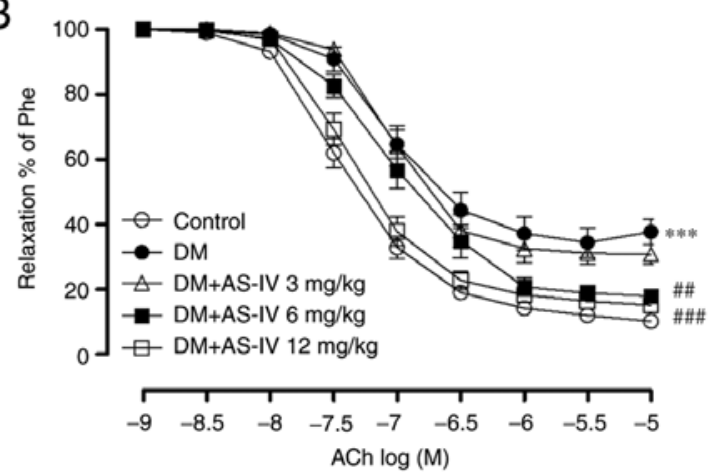

C

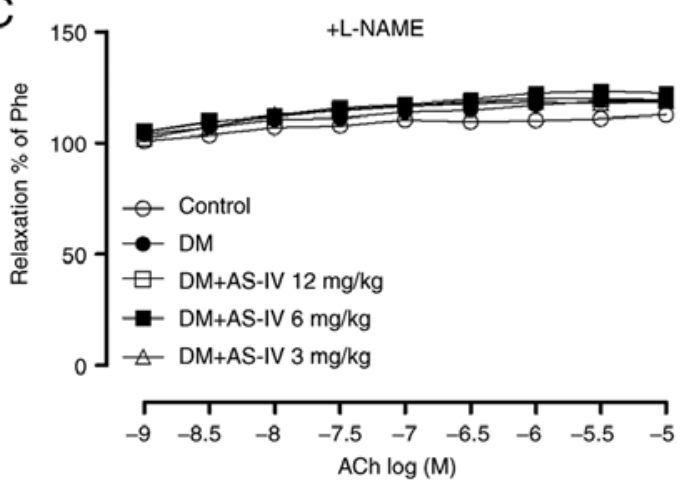

Figure 1. Effect of AS-IV on the EDRs of aortas obtained from diabetic mice. (A) Representative recording traces revealed that impaired ACh-induced aortic EDRs from DM mice were restored following treatment with AS-IV $(12 \mathrm{mg} / \mathrm{kg})$. ACh $\left(10^{-9}, 10^{-8.5}, 10^{-8}, 10^{-7.5}, 10^{-7}, 10^{-6.5}, 10^{-6}, 10^{-5.5}, 10^{-5} \mathrm{M}\right)$ was applied to the organ bath at points indicated by solid black spots. (B) Summative graphs demonstrated that AS-IV (6 and $12 \mathrm{mg} / \mathrm{kg})$ treatment improved aortic EDRs in DM mice. (C) EDRs in response to ACh following 30 min exposure to L-NAME were presented in aortas obtained from the 5 groups of mice. Data are presented as the mean \pm SEM $(n=6-8) .{ }^{* * *} \mathrm{P}<0.001$ vs. control mice. ${ }^{\# \#} \mathrm{P}<0.01$ and ${ }^{\# \# \#} \mathrm{P}<0.001$ vs. mice with DM. AS-IV, Astragaloside IV; EDRs, endothelium-dependent relaxations; DM, diabetes mellitus; ACh, acetylcholine; L-NAME, $\mathrm{N}^{\mathrm{G}}$-nitro-L-arginine; Phe, phenylephrine.

concentrations of ACh in Phe-precontracted segments of aortae were significantly reduced in DM mice compared with those in control mice. In contrast, AS-IV $(6$ and $12 \mathrm{mg} / \mathrm{kg})$ treatment can improve the impaired response compared with the DM group. However, after pre-incubation of aortic segments with L-NAME, a nitric oxide (NO) synthase inhibitor that can block the production of endothelium-derived NO, the recovery effect of AS-IV to EDR was abolished (Fig. 1C).

Furthermore, the endothelium-dependent contraction (EDC) in STZ-induced diabetic mice was also detected. As demonstrated in Fig. 2 and Table I, ACh-induced contractions increased with accumulative concentration in DM mice compared with the control. Compared with the DM group, AS-IV (6 and $12 \mathrm{mg} / \mathrm{kg}$ ) treatment significantly inhibited the EDC response.

$A S-I V$ increases NO activity in the aortae of STZ-induced diabetic mice. To characterize and localize NO content within the vascular wall, green fluorescence was analyzed in sections of aorta incubated with DAF-2 DA (Fig. 3A). As presented in Fig. 3B, compared with the control, fluorescence intensity was greatly inhibited in the DM group. As demonstrated in Fig. 3C and D, AS-IV-treatment reversed aortic NO levels in a dose-dependent manner, particularly at concentrations of 6 and $12 \mathrm{mg} / \mathrm{kg}$. Phosphorylated eNOS $\left(\mathrm{p}^{1177} \mathrm{eNOS}\right)$, the active form of eNOS, was also increased following AS-IV treatment, which was significant at the $12 \mathrm{mg} / \mathrm{kg}$ dosage.

$A S-I V$ inhibits ROS activity in the aortae of STZ-induced diabetic mice. ROS activity was detected through red fluorescence, which was analyzed via DHE incubation (Fig. 4A). Fluorescence intensity calculated from the aortic rings of mice with DM revealed markedly increased red staining compared with control mice, which was inhibited following $12 \mathrm{mg} / \mathrm{kg}$ AS-IV treatment (Fig. 4B). The activity of SOD and MDA in serum was examined to further test ROS levels. As presented in Fig. 4C and D, serum SOD activity was significantly decreased and MDA was increased in mice with DM compared with that in control mice. AS-IV treatment increased SOD activity and decreased MDA content when compared with mice with DM. The effect demonstrated by AS-IV was significant at concentrations of 6 and $12 \mathrm{mg} / \mathrm{kg}$.

AS-IV ameliorates NADPH oxidase activity in the aortae of STZ-induced diabetic mice. The expression of NADPH oxidase subunits, including p22phox, p47phox, p67phox, NOX2, NOX4 and Rac-1, were examined in the present study (Fig. 5). Compared with the control group, mice with DM exhibited increased levels of expression. However, AS-IV treatment decreased the expression each subunit, with the most significant effect being demonstrated at the $12 \mathrm{mg} / \mathrm{kg}$ dosage. 
A

Control
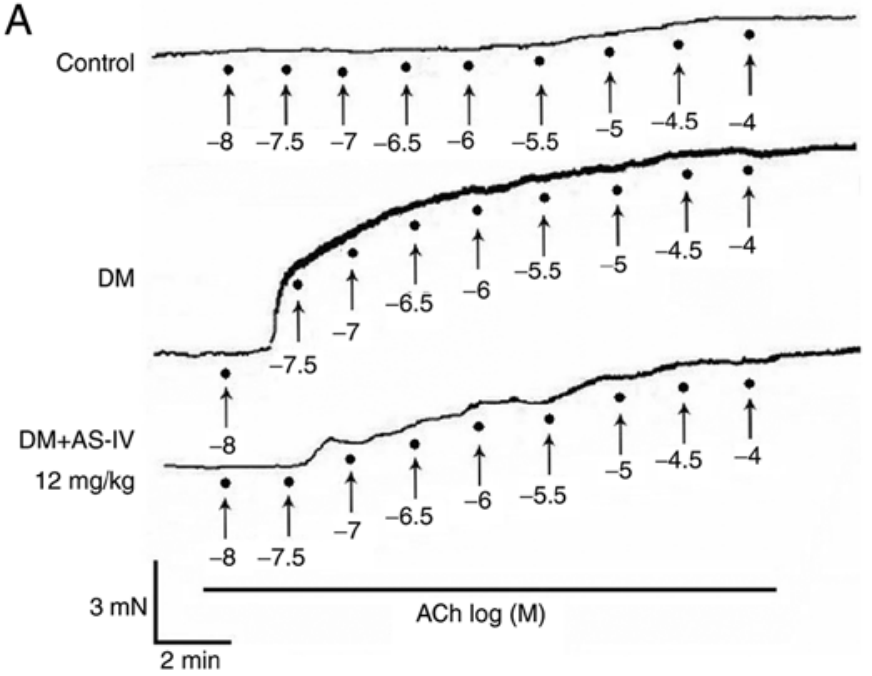

B

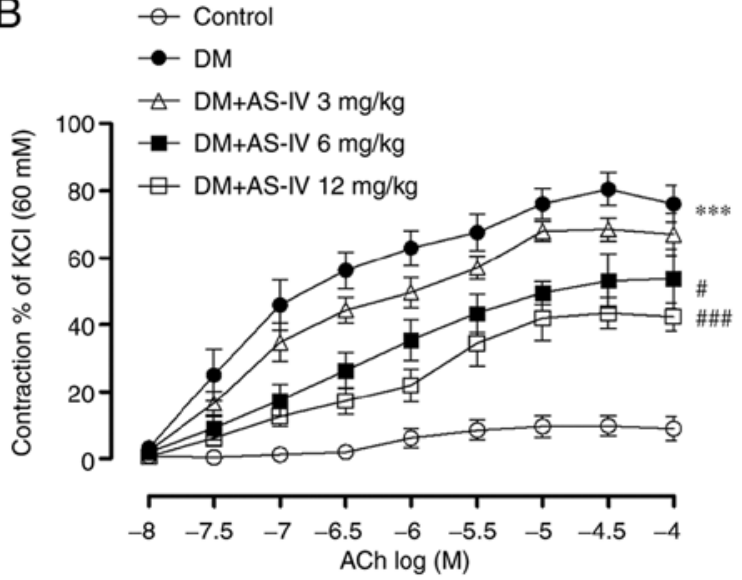

Figure 2. Effect of AS-IV on ACh-induced vasoconstriction in the aortae of diabetic mice. (A) Representative recording traces demonstrated that augmented ACh-induced EDCs in the aortae of DM mice were prevented following AS-IV $(12 \mathrm{mg} / \mathrm{kg})$ treatment. ACh $\left(10^{-8}, 10^{-7.5}, 10^{-7}, 10^{-6.5}, 10^{-6}, 10^{-5.5}, 10^{-5}, 10^{-4.5}, 10^{-4} \mathrm{M}\right)$ was applied to the organ bath at points indicated by solid black spots. (B) Summative graphs revealed that AS-IV (6 and $12 \mathrm{mg} / \mathrm{kg})$ treatment reduced EDCs in the aortae of DM mice. Data are presented as the mean \pm SEM $(n=6-8) .{ }^{* * * *} \mathrm{P}<0.001$ vs. control mice; ${ }^{*} \mathrm{P}<0.05$ and ${ }^{\# \# \#} \mathrm{P}<0.001$ vs. mice with DM. AS-IV, Astragaloside IV; ACh, acetylcholine; DM, diabetes mellitus; EDCs, endothelium-dependent contractions.

A
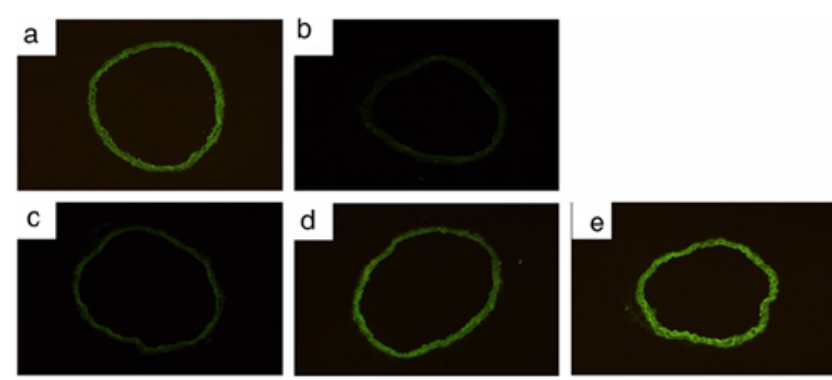

B

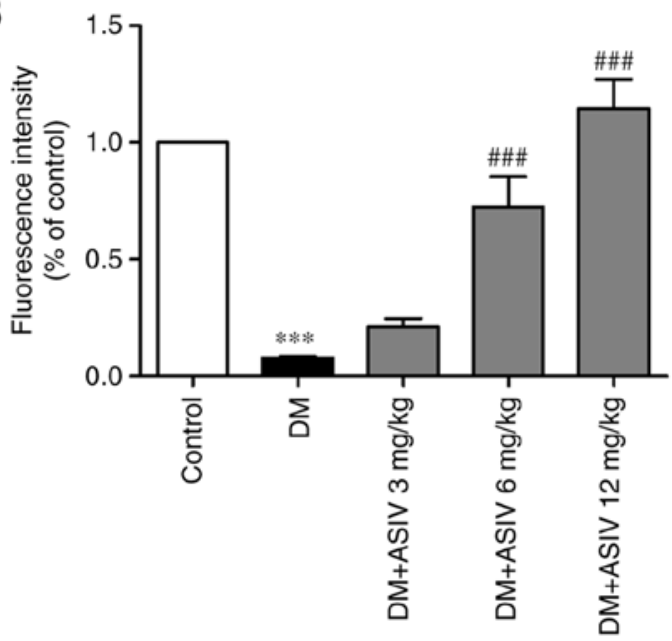

C

eNOS

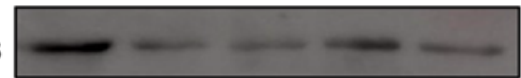

$\mathrm{p}^{1177}$ eNOS

$\beta$-actin

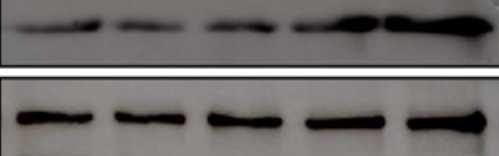

D

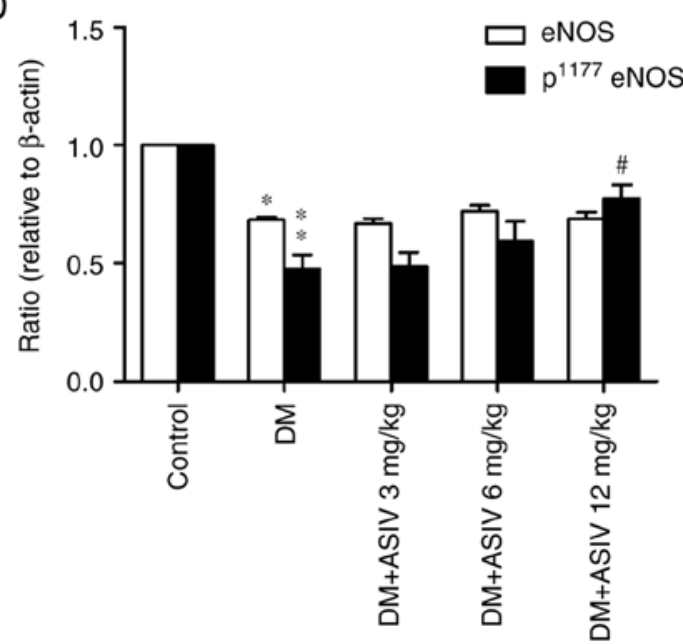

Figure 3. Effect of AS-IV on the activity of NO in the aortae of diabetic mice. (A) Representative photomicrographs of 4,5-diaminofluorescein diacetate-stained thoracic aorta sections from (a) control, (b) DM and (c) 3, (d) 6 and (e) $12 \mathrm{mg} / \mathrm{kg}$ DM+AS-IV groups (magnification, x200). (B) Analysis of fluorescence intensity of NO from (A). (C) Western blot analysis of eNOS and $\mathrm{p}^{1177} \mathrm{eNOS}$. (D) Analysis of eNOS and $\mathrm{p}^{1177}$ eNOS from (C). Data are presented as the mean \pm SEM ( $\mathrm{n}=4-6) .{ }^{*} \mathrm{P}<0.05,{ }^{* *} \mathrm{P}<0.01$ and ${ }^{* * *} \mathrm{P}<0.001$ vs. the control group. ${ }^{\#} \mathrm{P}<0.05$ and ${ }^{\# \# \#} \mathrm{P}<0.001$ vs. the DM group. AS-IV, Astragaloside IV; DM, diabetes mellitus; NO, nitric oxide; eNOS, endothelial nitric oxide synthase; p, phosphorylated. 
A
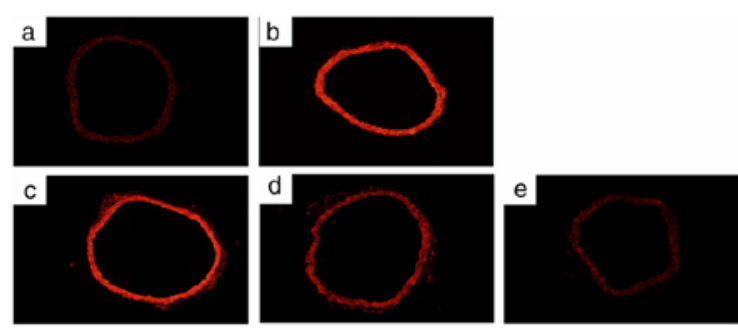

C

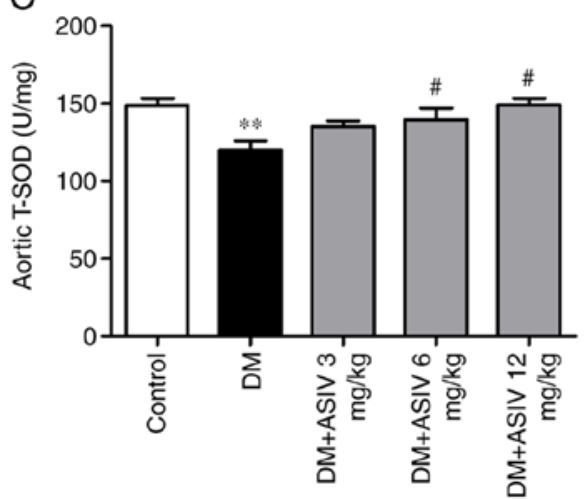

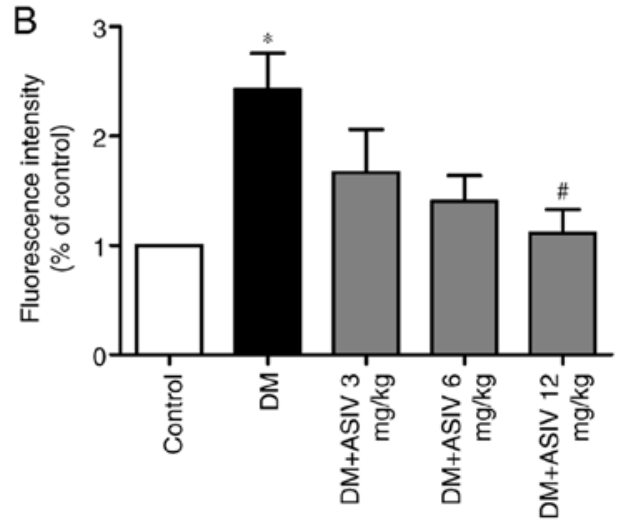

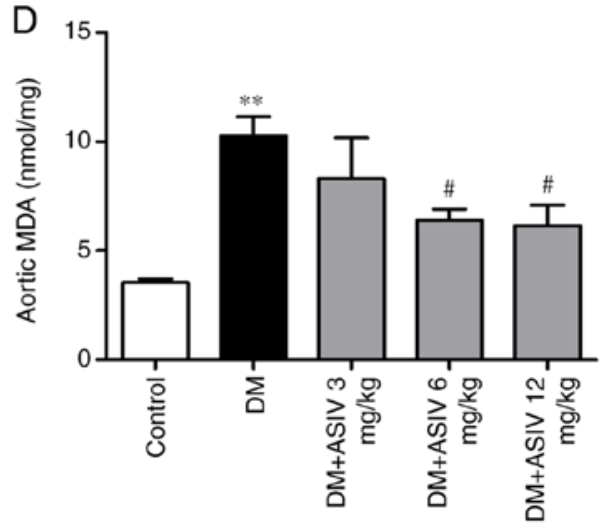

Figure 4. Effect of AS-IV on ROS generation in the aortae of diabetic mice. (A) Representative photomicrographs of dihydroethidium-stained thoracic aorta sections from the (a) control, (b) DM and at (c) 3, (d) 6 and (e) $12 \mathrm{mg} / \mathrm{kg}$ DM+AS-IV groups (magnification, x200). (B) Analysis of ROS fluorescence intensity from (A). ELISA analysis of aortic (C) T-SOD (U/ml) and (D) malondialdehyde (mmol/mg). Data are presented as the mean \pm SEM ( $\mathrm{n}=6-8)$. ${ }^{*} \mathrm{P}<0.05$ and ${ }^{* *} \mathrm{P}<0.01$ vs. the control group. ${ }^{*} \mathrm{P}<0.05$ vs. the DM group. AS-IV, Astragaloside IV; DM, diabetes mellitus; ROS, reactive oxygen species; T-SOD, superoxide dismutase; T-SOD, Total-superoxide dismutase; MDA, malondialdehyde.

Significant alterations were observed in p22phox, p47phox, NOX2, NOX4 and Rac-1 expression.

\section{Discussion}

Endothelial dysfunction is characterized by reduced NO bioavailability, which is considered to be one of the initial pathological events in the pathogenesis of diabetes-associated cardiovascular disorders $(29,30)$. In physiological and pathological conditions, the endothelium controls the tone of the underlying vascular smooth muscle cells through NO production (31). Previous studies have demonstrated that hyperglycemia-induced damage in endothelial cells is associated with decreased NO bioavailability in vascular beds $(32,33)$. Thus, improving endothelial function, particularly NO bioavailability, is an attractive therapeutic intervention for the prevention and treatment of cardiovascular complications. In the present study, impaired vasorelaxation and vasocontraction were confirmed in the aortic rings of STZ-induced diabetic mice. However, treatment with AS-IV restored each impairment in a concentration-dependent manner. Additionally, L-NAME, an inhibitor of NO synthase, abolished the protective effect of AS-IV, as demonstrated by higher maximal vasorelaxations in response to $\mathrm{ACh}$, suggesting that the efficacy of the compound was endothelium-dependent.

Abnormal NO generation, hyperglycemia, dyslipidemia and insulin resistance are important causal factors for the development of DM associated endothelial dysfunction (34). A previous study reported that reduced endothelial NO production is often associated with the inhibition of eNOS activity in diabetes-induced vascular dysfunction (35). In accordance with the decrease of endothelium-dependent vasodilatation in mice with DM, the current study revealed that NO bioavailability also decreased. However, AS-IV treatment increased NO bioavailability in a concentration-dependent manner. This further confirmed the potential effect of AS-IV on diabetic-induced aortic tissue injury by enhancing NO bioavailability. When assessing NO generation, the current study also revealed that DAF-2DA green fluorescence was present throughout the arterial wall, including in the media. DAF-2DA green fluorescence is usually considered as one of the direct detection methods of intracellular NO (36). However, immunohistochemistry revealed strong eNOS staining in vessel walls, specifically localizing to the intima. This method may therefore be used to identify sites of NO production in intima, vessel walls and other heterogeneous tissues. DAF fluorescence and chemiluminescence may produce substantially different results depending on the conditions and systems under investigation $(36,37)$. A previous study demonstrated that the different relaxing capacities of NO for smooth muscle cell contractions initiated by depolarization (high $\mathrm{K}^{+}$) or by $\alpha 1$ adrenoceptor stimulation is not dependent on the source of NO (endogenous or exogenous), but depends primarily on the pathways of $\left(\mathrm{Ca}^{2+}\right)_{\mathrm{i}}$ mobilization during the 
A

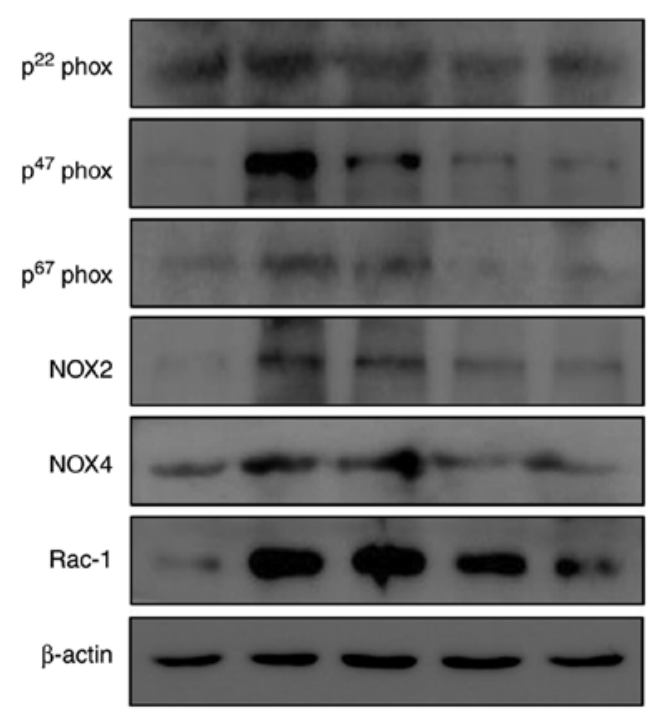

$\mathrm{D}$

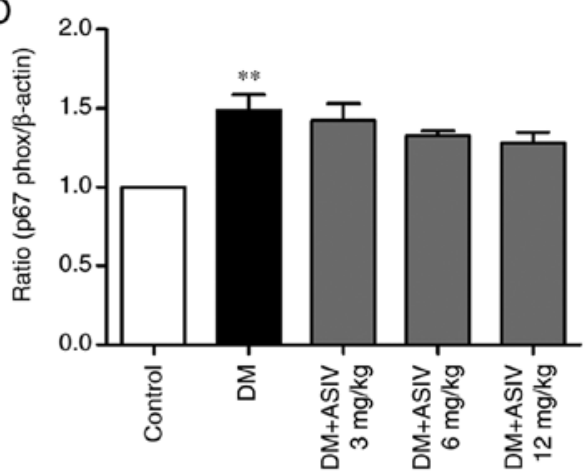

$\mathrm{F}$

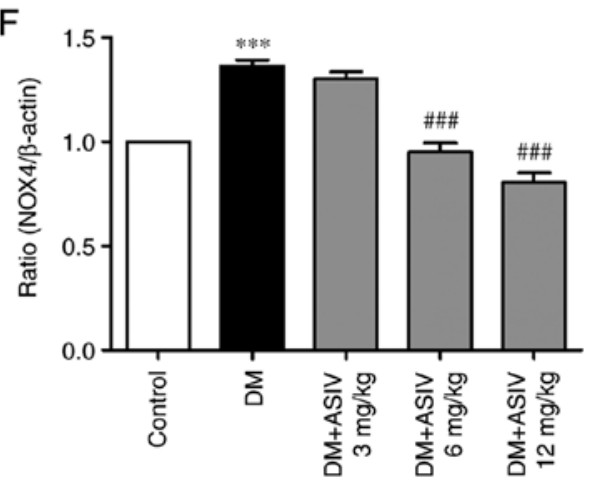

B

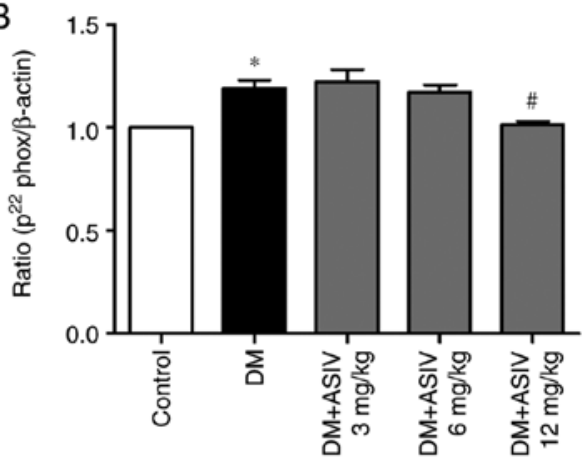

C

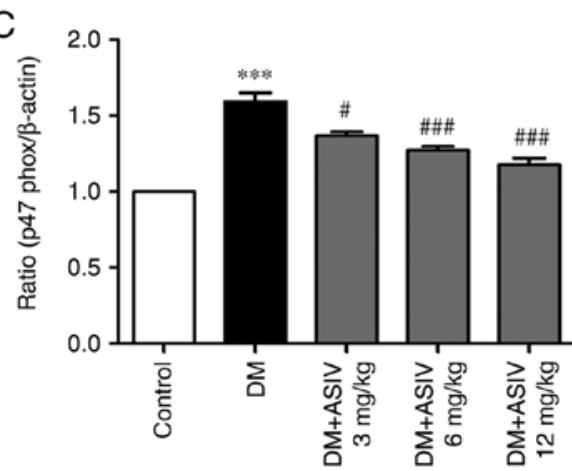

$\mathrm{E}$

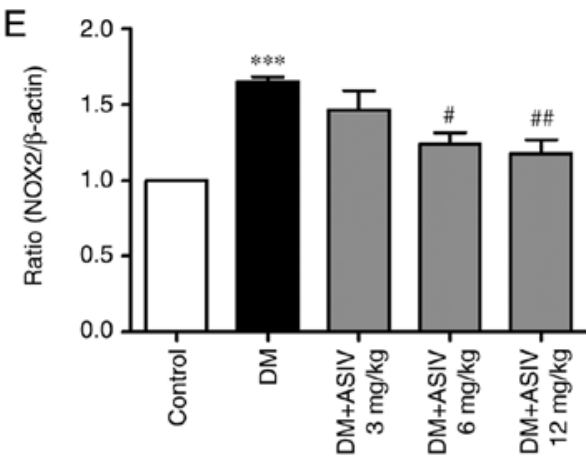

G

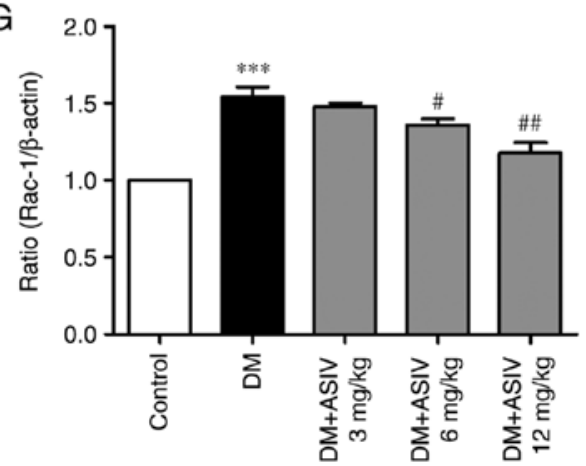

Figure 5. Effect of Astragaloside IV on NADPH oxidase in the aortae of diabetic mice. (A) Western blot analysis of various NADPH oxidase subunits, including p22phox, p47phox, p67phox, NOX2, NOX4 and Rac-1. (B) p22phox, (C) p47phox, (D) p67phox, (E) NOX2, (F) NOX4 and (G) Rac-1 levels were then statistically analyzed. Data are presented as the mean $\pm \mathrm{SEM}(\mathrm{n}=4-6) .{ }^{*} \mathrm{P}<0.05,{ }^{* *} \mathrm{P}<0.01$ and ${ }^{* * *} \mathrm{P}<0.001$ vs. the control group. ${ }^{\#} \mathrm{P}<0.05,{ }^{\# \#} \mathrm{P}<0.01$ and ${ }^{\# \# \#} \mathrm{P}<0.001$ vs. the DM group. AS-IV, Astragaloside IV; DM, diabetes mellitus; p22phox, human neutrophil cytochrome $b$ light chain; p47phox, neutrophil cytosolic factor 1; p67phox, neutrophil cytosolic factor 2; NOX, NADPH oxidase.

contraction of murine aortas (38). DAF fluorescence may therefore not be an independent indicator of NO. Since NO biosynthesis in vascular endothelial cells is undisputable, positive DAF-2DA fluorescence in vessel walls may be regarded as an internal positive control (37). The results of the current study are congruent with those of a previous study in which DAF-2DA green fluorescence was indicative of NO activity (28). 


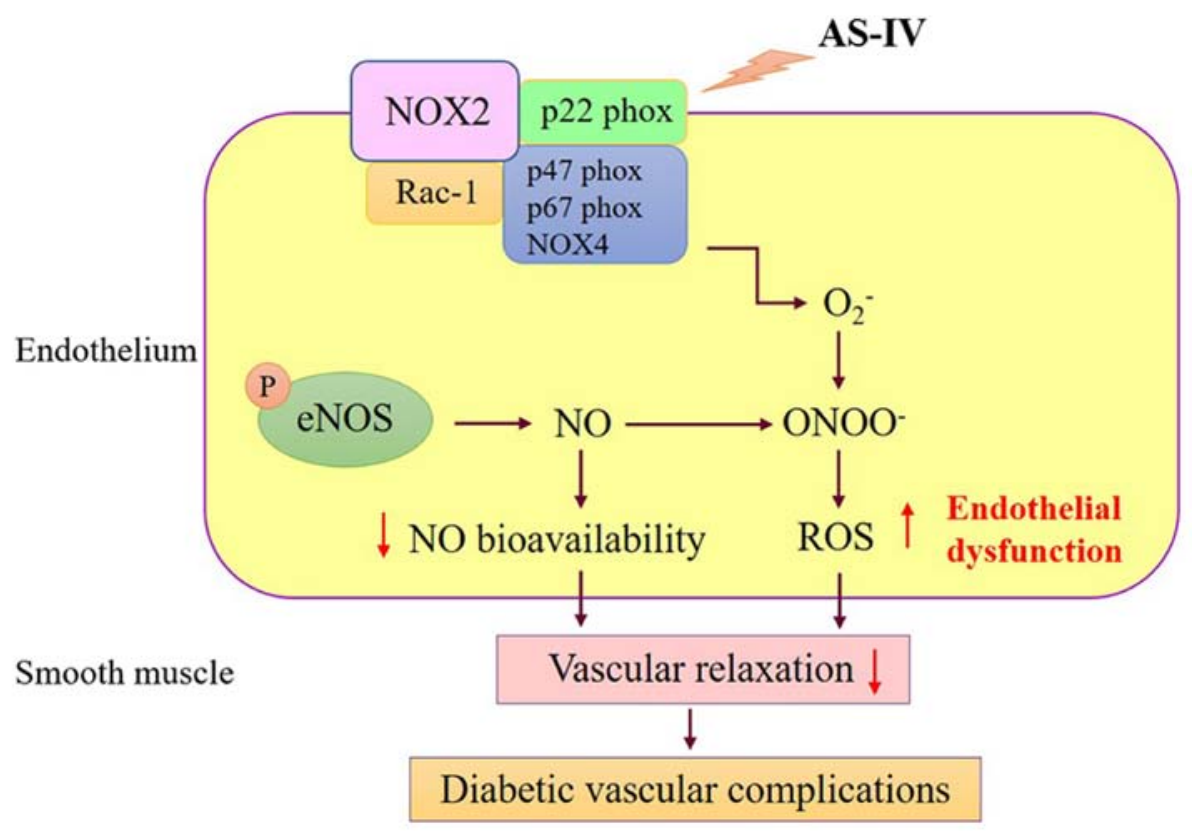

Figure 6. Proposed molecular model of AS-IV improving oxidative stress during endothelial dysfunction. AS-IV, Astragaloside IV; NOX, NADPH oxidase; p22phox, human neutrophil cytochrome $b$ light chain; p47phox, neutrophil cytosolic factor 1; p67phox, neutrophil cytosolic factor 2; eNOS, endothelial nitric oxide synthase; $p$, phosphorylated; NO, nitric oxide; ROS, reactive oxygen species.

Improvement of endothelial NO production and the prevention of vascular oxidative stress are other reasonable therapeutic strategies for the treatment of DM, targeting diabetic endothelial progenitor cells (39). ROS, which include hydrogen peroxide $\left(\mathrm{H}_{2} \mathrm{O}_{2}\right)$, superoxide anion $\left(\mathrm{O}_{2}{ }^{-}\right)$, hydroxyl radicals $(\mathrm{OH})$ and peroxynitrite anion $\left(\mathrm{ONOO}^{-}\right)$, play important signaling roles under physiological conditions at moderate concentrations (40). However, during excessive or sustained ROS production, where production exceeds the available antioxidant defenses, oxidative stress occurs (41). The diabetic production of excessive endothelial ROS is the main reason for the pathogenesis of vascular complications $(11,42)$. The current study demonstrated that ROS generation increased in mice with DM. Additionally, levels of MDA, a marker of ROS-induced lipid peroxidation, also significantly increased, which was accompanied by decreased SOD activities in aortic tissue. These data indicated the presence of oxidative stress in the aortas of STZ-induced diabetic mice.

Oxidative stress due to exaggerated NOX-induced ROS formation and decreased NO bioavailability is a hallmark of diabetic vasculopathy. Although the suppression of ROS and restoration of $\mathrm{NO}$ bioactivity are two strategies employed by antioxidants, each are closely associated as eNOS uncoupling can lead to the production of superoxide anions rather than $\mathrm{NO}$, resulting in the increased production of vascular ROS $(43,44)$. Additionally, ROS as well as peroxynitrite, a potent oxidant produced by the interaction of superoxide anions with NO, can further induce eNOS uncoupling, reduce endothelium-derived NO required for vascular relaxation and modify endothelial cell molecules via oxidation $(40,45)$. Superoxide quenches $\mathrm{NO}$ and impairs the endothelial-derived vasodilator system. Therefore, it is reasonable to speculate that the generation of NOX-derived ROS may be associated with decreased NO bioavailability and vascular dysfunction (46).
NOX is the major source of ROS in the vasculature, which exerts effects under physiological and pathological conditions. NOX is also considered to be the trigger of development of diabetic endothelial dysfunction (47). The NO family is composed of catalytic subunits (NOX1, 2, 3, 4 and 5) and a docking subunit, p22phox, both of which are present in the cell membrane. Regulatory subunits, including p47phox, p67phox or homologs, are located in the cytosol (46). The activation of Rac-1, a key event in NOX activation, regulates the translocation and assembly of NOX subunits in the plasma membrane (48). Although NOXs are differentially expressed in the vascular wall and have expression profiles that vary in different disease states, it is accepted that the expression of NOXs increase in response to certain stimuli such as hyperglycemia, which eventually results in the disruption of vascular homeostasis (49). NOX4 is the major source of ROS in endothelial cells. Therefore, increased NOX4 expression is associated with the early progression of vascular disease $(50,51)$. Increased endothelial NOX2 levels contributes to angiotensin II-induced endothelial dysfunction, vascular remodeling and hypertension (52). Other NOX organizers, such as NOX1 and p47phox, are mediators of diabetes-induced vascular dysfunction in mice (53). Considering the potentially important role of NOX in the pathogenesis of cardiovascular complications in patients with diabetes, the application of NOX inhibitors may serve as a viable therapeutic target. The current study revealed that AS-IV inhibited the expression of p22phox, p47phox, NOX2, NOX4 and Rac-1, which indicated that AS-IV inhibited endothelial dysfunction through the oxidative stress pathway (Fig. 6).

In summary, the present study demonstrated that AS-IV inhibited endothelial dysfunction in the aortas of STZ-induced diabetic mice, which was associated with the attenuation of 
NADPH oxidase expression, the attenuation of ROS production and the promotion of NO production.

\section{Acknowledgements}

Not applicable.

\section{Funding}

The current study was supported by the Innovation Program of Talent Project of Putuo District (grant no. 2020360A), the National Natural Science Foundation of China (grant no. 81403235), the Key Medical Discipline Project of Shanghai Municipal Health Bureau (grant no. ZK2019A12) and the Independent Innovation Research Fund of Putuo District Science and Technology Committee (grant no. 2012PTKW006).

\section{Availability of data and materials}

The datasets used and/or analyzed during the current study are available from the corresponding author on reasonable request.

\section{Authors' contributions}

LW and HW participated in the design and coordination, and guaranteed the integrity of the entire study. YZ, XDM, ALC, SC and ZJL carried out the experiments. YMW and WP performed statistical analysis and edited the manuscript. LW was involved in drafting the manuscript, evaluated the statistical analysis and critically revised the manuscript. LW and HW confirm the authenticity of all the raw data. All authors read and approved the final manuscript.

\section{Ethics approval and consent to participate}

All experimental procedures involving animals were conducted in accordance with the National Institutes of Health Guide for the Care and Use of Laboratory Animals and were approved by the Ethics Committee of Putuo Hospital, Shanghai University of Traditional Chinese Medicine.

\section{Patients consent for publication}

Not applicable.

\section{Competing interests}

The authors declare that they have no competing interests.

\section{References}

1. Akalin S, Berntorp K, Ceriello A, Das AK, Kilpatrick ES, Koblik T, Munichoodappa CS, Pan CY, Rosenthall W, Shestakova M, et al: Intensive glucose therapy and clinical implications of recent data: A consensus statement from the global task force on glycaemic control. Int J Clin Pract 63: 1421-1425, 2009.

2. Preis SR, Pencina MJ, Hwang SJ, D'Agostino RB Sr, Savage PJ, Levy D and Fox CS: Trends in cardiovascular disease risk factors in individuals with and without diabetes mellitus in the Framingham heart study. Circulation 120: 212-220, 2009.
3. Castro-Correia C, Maia ML, Norberto S, Costa-Santos C, Barroso MF, Carvalho A, Fontoura M, Domingues V and Calhau C: Can antioxidative status be involved in type 1 diabetes? J Clin Med Res 9: 998-1001, 2017.

4. McCarthy O, Moser O, Eckstein ML, Bain SC, Pitt J and Bracken R: Supplementary nitric oxide donors and exercise as potential means to improve vascular health in people with type 1 diabetes: Yes to no? Nutrients 11: 1571, 2019.

5. Giugliano D, Ceriello A and Paolisso G: Diabetes mellitus, hypertension, and cardiovascular disease: Which role for oxidative stress? Metabolism 44: 363-368, 1995.

6. Evans JL, Goldfine ID, Maddux BA and Grodsky GM: Are oxidative stress-activated signaling pathways mediators of insulin resistance and beta-cell dysfunction? Diabetes 52: 1-8, 2003.

7. Gori T and Münzel T: Oxidative stress and endothelial dysfunction: Therapeutic implications. Ann Med 43: 259-272, 2011.

8. Kurosaki Y, Imoto A, Kawakami F, Yokoba M, Takenaka T, Ichikawa T, Katagiri $\mathrm{M}$ and Ishii $\mathrm{N}$ : Oxidative stress increases megalin expression in the renal proximal tubules during the normoalbuminuric stage of diabetes mellitus. Am J Physiol Renal Physiol 314: F462-F470, 2018.

9. Salisbury D and Bronas U: Reactive oxygen and nitrogen species: Impact on endothelial dysfunction. Nurs Res 64: 53-66, 2015.

10. Sáez T, Salsoso R, Leiva A, Toledo F, de Vos P, Faas M and Sobrevia L: Human umbilical vein endothelium-derived exosomes play a role in foetoplacental endothelial dysfunction in gestational diabetes mellitus. Biochim Biophys Acta Mol Basis Dis 1864: 499-508, 2018.

11. Ambasta RK, Kohli $\mathrm{H}$ and Kumar P: Multiple therapeutic effect of endothelial progenitor cell regulated by drugs in diabetes and diabetes related disorder. J Transl Med 15: 185, 2017.

12. Burtenshaw D, Hakimjavadi R, Redmond EM and Cahill PA: Nox, reactive oxygen species and regulation of vascular cell fate. Antioxidants (Basel) 6: 90, 2017.

13. Dong J, Wong SL, Lau CW, Lee HK, Ng CF, Zhang L, Yao X, Chen ZY, Vanhoutte PM and Huang Y: Calcitriol protects renovascular function in hypertension by down-regulating angiotensin II type 1 receptors and reducing oxidative stress. Eur Heart J 33: 2980-2990, 2012.

14. Buday A, Orsy P, Godó M, Mózes M, Kökény G, Lacza Z, Koller A, Ungvári Z, Gross ML, Benyó Z and Hamar P: Elevated systemic TGF-beta impairs aortic vasomotor function through activation of NADPH oxidase-driven superoxide production and leads to hypertension, myocardial remodeling, and increased plaque formation in apoE(-/-) mice. Am J Physiol Heart Circ Physiol 299: H386-H395, 2010.

15. Wang X, Zhao S, Su M, Sun L, Zhang S, Wang D, Liu Z, Yuan Y, Liu Y and Li Y: Geraniol improves endothelial function by inhibiting NOX-2 derived oxidative stress in high fat diet fed mice. Biochem Biophys Res Commun 474: 182-187, 2016.

16. Li J, Huang L, Wang S, Yao Y and Zhang Z: Astragaloside IV attenuates inflammatory reaction via activating immune function of regulatory T-cells inhibited by HMGB1 in mice. Pharm Biol 54: 3217-3225, 2016.

17. Zhang N, Wang XH, Mao SL and Zhao F: Astragaloside IV improves metabolic syndrome and endothelium dysfunction in fructose-fed rats. Molecules 16: 3896-3907, 2011.

18. Guo H, Cao A, Chu S, Wang Y, Zang Y, Mao X, Wang H, Wang Y, Liu C, Zhang X and Peng W: Astragaloside IV attenuates podocyte apoptosis mediated by endoplasmic reticulum stress through upregulating sarco/endoplasmic reticulum $\mathrm{Ca}^{2+-}$ ATPase 2 expression in diabetic nephropathy. Front Pharmacol 7: 500, 2016.

19. Wang L, Chi YF, Yuan ZT, Zhou WC, Yin PH, Zhang XM, Peng W and Cai H: Astragaloside IV inhibits renal tubulointerstitial fibrosis by blocking TGF- $\beta /$ Smad signaling pathway in vivo and in vitro. Exp Biol Med (Maywood) 239: 1310-1324, 2014.

20. Motomura K, Fujiwara Y, Kiyota N, Tsurushima K, Takeya M, Nohara T, Nagai R and Ikeda T: Astragalosides isolated from the root of astragalus radix inhibit the formation of advanced glycation end products. J Agric Food Chem 57: 7666-7672, 2009.

21. Guo H, Wang Y, Zhang X, Zang Y, Zhang Y, Wang L, Wang H, Wang Y, Cao A and Peng W: Astragaloside IV protects against podocyte injury via SERCA2-dependent ER stress reduction and AMPK $\alpha$-regulated autophagy induction in streptozotocin-induced diabetic nephropathy. Sci Rep 7: 6852, 2017.

22. Qiao Y, Fan CL and Tang MK: Astragaloside IV protects rat retinal capillary endothelial cells against high glucose-induced oxidative injury. Drug Des Devel Ther 11: 3567-3577, 2017. 
23. Wang N, Siu F and Zhang Y: Effect of astragaloside IV on diabetic gastric mucosa in vivo and in vitro. Am J Transl Res 9: 4902-4913, 2017.

24. Yu WN, Sun LF and Yang H: Inhibitory effects of astragaloside IV on bleomycin-induced pulmonary fibrosis in rats via attenuation of oxidative stress and inflammation. Inflammation 39: 1835-1841, 2016.

25. Sun J, Chen XL,Zheng JY, Zhou JW and Ma ZL: Astragaloside IV protects new born rats from anesthesia-induced apoptosis in the developing brain. Exp Ther Med 12: 1829-1835, 2016.

26. Gu DM, Lu PH,Zhang K, Wang X, Sun M, Chen GQ and Wang Q: EGFR mediates astragaloside IV-induced Nrf2 activation to protect cortical neurons against in vitro ischemia/reperfusion damages. Biochem Biophys Res Commun 457: 391-397, 2015.

27. Reagan-Shaw S, Nihal M and Ahmad N: Dose translation from animal to human studies revisited. FASEB J 22: 659-661, 2008.

28. Chu S, Wang L, Mao XD and Peng W: Improvement of huangqi decoction on endothelial dysfunction in 5/6 nephrectomized rats. Cell Physiol Biochem 40: 1354-1366, 2016.

29. Kawano N, Emoto M, Mori K, Yamazaki Y, Urata H, Tsuchikura S, Motoyama K, Morioka T, Fukumoto S, Shoji T, et al: Association of endothelial and vascular smooth muscle dysfunction with cardiovascular risk factors, vascular complications, and subclinical carotid atherosclerosis in type 2 diabetic patients. J Atheroscler Thromb 19: 276-284, 2012.

30. Islam MZ, Van Dao C, Miyamoto A and Shiraishi M: Rho-kinase and the nitric oxide pathway modulate basilar arterial reactivity to acetylcholine and angiotensin II in streptozotocin-induced diabetic mice. Naunyn Schmiedebergs Arch Pharmacol 390: 929-938, 2017.

31. Guo Z, Zhang Y, Liu C, Youn JY and Cai HL: Toll-like Receptor 2 (TLR2) deficiency abrogates diabetic and obese phenotypes while restoring endothelial function via inhibition of NOX1. Diabetes: Jun 14, 2021 (Epub ahead of print). doi: 10.2337/ db20-0591.

32. Varghese JF, Patel R and Yadav UCS: Novel insights in the metabolic syndrome-induced oxidative stress and inflammation-mediated atherosclerosis. Curr Cardiol Rev 14: 4-14, 2018.

33. Versari D, Daghini E, Virdis A, Ghiadoni L and Taddei S Endothelial dysfunction as a target for prevention of cardiovascular disease. Diabetes Care 32 (Suppl 2): S314-S321, 2009

34. Tangvarasittichai S: Oxidative stress, insulin resistance, dyslipidemia and type 2 diabetes mellitus. World J Diabetes 6: 456-480, 2015.

35. Cicek FA, Kandilci HB and Turan B: Role of ROCK upregulation in endothelial and smooth muscle vascular functions in diabetic rat aorta. Cardiovasc Diabetol 12: 51, 2013.

36. Schwendemann J, Sehringer B, Noethling C, Zahradnik HP and Schaefer WR: Nitric oxide detection by DAF (diaminofluorescein) fluorescence in human myometrial tissue. Gynecol Endocrinol 24: 306-311, 2008

37. Planchet $E$ and Kaiser WM: Nitric oxide (NO) detection by DAF fluorescence and chemiluminescence: A comparison using abiotic and biotic NO sources. J Exp Bot 57: 3043-3055, 2006.

38. Van Hove CE, Van der Donckt C, Herman AG, Bult $\mathrm{H}$ and Fransen P: Vasodilator efficacy of nitric oxide depends on mechanisms of intracellular calcium mobilization in mouse aortic smooth muscle cells. Br J Pharmacol 158: 920-930, 2009.

39. Cao W, Cui J, Li S, Zhang D, Guo Y, Li Q, Luan Y and Liu X: Crocetin restores diabetic endothelial progenitor cell dysfunction by enhancing NO bioavailability via regulation of PI3K/AKT-eNOS and ROS pathways. Life Sci 181: 9-16, 2017.
40. Magenta A, Greco S, Capogrossi MC, Gaetano C and Martelli F: Nitric oxide, oxidative stress, and p66Shc interplay in diabetic endothelial dysfunction. Biomed Res Int 2014: 193095, 2014.

41. Förstermann U, Xia N and Li H: Roles of vascular oxidative stress and nitric oxide in the pathogenesis of atherosclerosis. Circ Res 120: 713-735, 2017.

42. Ding X, Zhang M, Gu R, Xu G and Wu H: Activated microglia induce the production of reactive oxygen species and promote apoptosis of co-cultured retinal microvascular pericytes. Graefes Arch Clin Exp Ophthalmol 255: 777-788, 2017.

43. Thum T, Fraccarollo D, Schultheiss M, Froese S, Galuppo P, Widder JD, Tsikas D, Ertl G and Bauersachs J: Endothelial nitric oxide synthase uncoupling impairs endothelial progenitor cell mobilization and function in diabetes. Diabetes 56: 666-674, 2007.

44. Hohenstein B, Hugo CP, Hausknecht B, Boehmer KP, Riess RH and Schmieder RE: Analysis of NO-synthase expression and clinical risk factors in human diabetic nephropathy. Nephrol Dial Transplant 23: 1346-1354, 2008.

45. Zhang BQ, Hu SJ, Qiu LH, Zhu JH, Xie XJ, Sun J, Zhu ZH, Xia Q and Bian K: Effects of Astragalus membranaceus and its main components on the acute phase endothelial dysfunction induced by homocysteine. Vascul Pharmacol 46: 278-285, 2007.

46. Holterman CE, Read NC and Kennedy CR: Nox and renal disease. Clin Sci (Lond) 128: 465-481, 2015.

47. Tian R, Ding Y, Peng YY and Lu N: Myeloperoxidase amplified high glucose-induced endothelial dysfunction in vasculature: Role of NADPH oxidase and hypochlorous acid. Biochem Biophys Res Commun 484: 572-578, 2017.

48. Drummond GR, Selemidis S, Griendling KK and Sobey CG: Combating oxidative stress in vascular disease: NADPH oxidases as therapeutic targets. Nat Rev Drug Discov 10: 453-471, 2011.

49. Konior A, Schramm A, Czesnikiewicz-Guzik M and Guzik TJ: NADPH oxidases in vascular pathology. Antioxid Redox Signal 20: 2794-2814, 2014

50. Zhao QD, Viswanadhapalli S, Williams P, Shi Q, Tan C, Yi X, Bhandari B and Abboud HE: NADPH oxidase 4 induces cardiac fibrosis and hypertrophy through activating Akt/mTOR and NFкB signaling pathways. Circulation 131: 643-655, 2015.

51. Lee HY, Zeeshan HMA, Kim HR and Chae HJ: Nox4 regulates the eNOS uncoupling process in aging endothelial cells. Free Radic Biol Med 113: 26-35, 2017

52. Murdoch CE, Alom-Ruiz SP, Wang M, Zhang M, Walker S, Yu B, Brewer A and Shah AM: Role of endothelial Nox 2 NADPH oxidase in angiotensin II-induced hypertension and vasomotor dysfunction. Basic Res Cardiol 106: 527-538, 2011

53. Rezende F, Moll F, Walter M, Helfinger V, Hahner F, Janetzko P, Ringel C, Weigert A, Fleming I, Weissmann N, et al: The NADPH organizers NoxO1 and p47phox are both mediators of diabetes-induced vascular dysfunction in mice. Redox Biol 15: 12-21, 2018

This work is licensed under a Creative Commons Attribution-NonCommercial-NoDerivatives 4.0 International (CC BY-NC-ND 4.0) License. 